\title{
Precipitation of heterogeneous nanostructures: Metal nanoparticles and dielectric nanocrystallites
}

\section{AUTHOR(S):}

Masai, Hirokazu; Takahashi, Yoshihiro; Fujiwara, Takumi; Tokuda, Yomei; Yoko, Toshinobu

\section{CITATION:}

Masai, Hirokazu ...[et al]. Precipitation of heterogeneous nanostructures: Metal nanoparticles and dielectric nanocrystallites. Journal of Applied Physics 2010, 108(2): 023503.

\section{ISSUE DATE:}

2010-07-19

URL:

http://hdl.handle.net/2433/128952

RIGHT:

(C) 2010 American Institute of Physics 


\title{
Precipitation of heterogeneous nanostructures: Metal nanoparticles and dielectric nanocrystallites
}

\author{
Hirokazu Masai, ${ }^{1, a), b)}$ Yoshihiro Takahashi, ${ }^{1}$ Takumi Fujiwara, ${ }^{1}$ Yomei Tokuda, ${ }^{2}$ and \\ Toshinobu Yoko ${ }^{2}$ \\ ${ }^{1}$ Department of Applied Physics, Tohoku University, 6-6-05, Aoba, Aoba-ku, Sendai 980-8579, Japan \\ ${ }^{2}$ Institute for Chemical Research, Kyoto University, Gokasyo, Uji, Kyoto 611-0011, Japan
}

(Received 21 December 2009; accepted 1 June 2010; published online 19 July 2010)

\begin{abstract}
Heterogeneous precipitation of nanocrystallites of metallic $\mathrm{Bi}$ and anatase was observed in $\mathrm{CaO}-\mathrm{Bi}_{2} \mathrm{O}_{3}-\mathrm{B}_{2} \mathrm{O}_{3}-\mathrm{Al}_{2} \mathrm{O}_{3}-\mathrm{TiO}_{2}$ glass-ceramics. Addition of AlN reduced the $\mathrm{Bi}_{2} \mathrm{O}_{3}$ to $\mathrm{Bi}$ metal nanoparticles, which were uniformly dispersed in the glass. After heat-treatment of the Bi-precipitated glass around the glass transition temperature, nanocrystalline anatase precipitated out without aggregation of the Bi metal particles. It was found that the anatase nanocrystal size was affected by the distance between a nanocrystal and a precipitated Bi nanoparticle. The glass-ceramic produced is a functional material containing a random dispersion of different types of nanoparticles with different dielectric constants. (C) 2010 American Institute of Physics. [doi:10.1063/1.3457790]
\end{abstract}

\section{INTRODUCTION}

Recently, functional materials containing heterogeneous regions have attracted much attention. Unique phenomena could originate not only in the heterogeneous regions but also at the interfaces in such hybrid structures, so the production of hybrid materials consisting of multiple components with different dielectric constants is an attractive target in various scientific areas.

One material of interest is a solid matrix containing dispersed nanoparticles (heterogeneous regions) because nanoparticles of well-controlled size can exhibit unique properties that depend on the particle size. Various applications, such as optical, electronic, photocatalytic, have been suggested, ${ }^{1-6}$ but the dispersion stability of the nanoparticles in the solidstate matrix is still a major problem because the performance will be adversely affected if the nanoparticles aggregate. Therefore, with respect to chemical stability and dispersibility, oxide glasses containing metal nanoparticles are promising candidates. However, uniformly dispersed metal nanoparticles in heat-treated glasses are restricted to a few metal colloids, such as $\mathrm{Au}, \mathrm{Ag}$, and $\mathrm{Cu}$, which are easily converted from cations to metals. ${ }^{7}$ Crystallization of oxide glasses is a conventional way of inducing heterogeneous regions in an otherwise isotropic material. Since glass-ceramics consist of both disordered glass regions and ordered crystalline regions, they not only have the merits of glass materials - they have high transparency and chemical durability and are easy to fabricate-but also have unique physical properties originating from the crystalline phase. ${ }^{8-14}$ Recently, we have reported the crystallization of an oxide semiconductor from transparent oxide glasses by conventional heat-treatment. ${ }^{11-14}$ Since the crystallization of a glass matrix is governed by its chemical composition, the selective crys-

\footnotetext{
${ }^{a)}$ Present address: Institute for Chemical Research, Kyoto University, Gokasyo Uji, Kyoto 611-0011, Japan.

b) Author to whom correspondence should be addressed. Electronic mail: masai_h@noncry.kuicr.kyoto-u.ac.jp.
}

tallization of an oxide semiconductor from a multicomponent glass monolith is an attractive potential method for the creation of functional optical materials. It is also notable that glass-ceramics containing $\mathrm{TiO}_{2}$ or $\mathrm{ZnO}$ are transparent, which does not cause light scattering even though the precipitated nanocrystallites have a high refractive index. ${ }^{11-14}$ The large difference between the refractive index of the nanocrystallites and that of the surrounding amorphous matrix makes these glass-ceramics potentially attractive as strong scattering media. ${ }^{15-17}$ However, it is difficult to introduce multiple heterogeneous phases such as metals and dielectrics into the same material because the crystallization of oxide glass is a thermodynamically stable process that produces dielectric materials at temperatures above the glass transition temperature $\left(T_{\mathrm{g}}\right)$. Although it has been reported that metal nanoparticles can be precipitated by laser irradiation, ${ }^{18-20}$ it is difficult to induce the bulk crystallization of metal nanoparticles.

Recently, Komatsu et al. ${ }^{21}$ reported the reduction of $\mathrm{Bi}_{2} \mathrm{O}_{3}$ to $\mathrm{Bi}$ metal by the addition of $20 \mathrm{~mol} \%$ AlN to $40 \mathrm{Bi}_{2} \mathrm{O}_{3}-60 \mathrm{~B}_{2} \mathrm{O}_{3}$ glass. Their report suggests that the addition of nitride to a glass melt results in the reduction in metal oxides. Since it has been suggested that reduction by nitrides occurs mainly in the melt, it is expected that the coprecipitation of oxide and metal nanocrystallites could be attained after heat-treatment at temperatures around the $T_{\mathrm{g}}$, at which the local migration of atoms occurs. It is also expected that the nucleation of oxide crystallites could be easily induced at the interface between metal nanoparticles and the surrounding amorphous region, where many structural defects will exist because of differences in structure and chemical composition.

For the coprecipitation of $\mathrm{Bi}$ metal nanoparticles and oxide crystallites, we selected $\mathrm{CaO}-\mathrm{Bi}_{2} \mathrm{O}_{3}-\mathrm{B}_{2} \mathrm{O}_{3}-\mathrm{Al}_{2} \mathrm{O}_{3}-$ $\mathrm{TiO}_{2}$ (CaBBAT) glass ${ }^{11}$ as the virgin glass. Conventional heat-treatment of the glass resulted in the selective crystallization of $\mathrm{TiO}_{2}$, and $\mathrm{Bi}$ clusters were precipitated by $\mathrm{XeCl}$ pulse laser irradiation. ${ }^{22}$ The formation of Bi clusters from 
the glass by laser irradiation suggests that $\mathrm{Bi}$ metal can also be possibly formed. Moreover, our recent finding that Bi-free $\mathrm{TiO}_{2}$ glass-ceramics can be prepared ${ }^{13}$ indicates that the formation of $\mathrm{Bi}$ nanoparticles and the precipitation of $\mathrm{TiO}_{2}$ can be independently controlled. We therefore examined the nanoscale coprecipitation, without laser irradiation, of $\mathrm{Bi}$ metal and $\mathrm{TiO}_{2}$ in oxide glass. In the present study, nitride was added to effect strong reduction in the glass matrix.

\section{EXPERIMENTAL}

The CaBBAT precursor glass was prepared by a conventional melt-quenching method. Batches consisting of $\mathrm{CaCO}_{3}$ (5 mmol), $\mathrm{B}_{2} \mathrm{O}_{3}(65 \mathrm{mmol}), \mathrm{Bi}_{2} \mathrm{O}_{3}(10 \mathrm{mmol}), \mathrm{TiO}_{2}(20$ $\mathrm{mmol})$, and $\mathrm{AlN}(5 \mathrm{mmol})$ were melted in a $50 \mathrm{~mL}$ alumina crucible at $1350{ }^{\circ} \mathrm{C}$ for $40 \mathrm{~min}$. Energy dispersive $\mathrm{x}$-ray spectroscopy (EDX) showed that the amount of $\mathrm{Al}_{2} \mathrm{O}_{3}$ eluted from the crucible was $25 \mathrm{~mol} \%$. The glass melt was quenched on a steel plate at $200{ }^{\circ} \mathrm{C}$ and then annealed at $577{ }^{\circ} \mathrm{C}$, which is $10 \mathrm{~K}$ below the $T_{\mathrm{g}}$, for $1 \mathrm{~h}$. After mechanical polishing, the glass sample was heat-treated in an electric furnace in an ambient atmosphere to obtain the corresponding glass-ceramic. The $T_{\mathrm{g}}$ and crystallization onset temperature $T_{\mathrm{x}}$ were measured by differential thermal analysis (DTA; Thermo Plus 8120; Rigaku Co. Ltd.) operated at a heating rate of $10 \mathrm{~K} \mathrm{~min}{ }^{-1}$. The absorption spectra were measured with a SHIMADZU UV3600 spectrometer. We performed $\mathrm{X}$-ray diffraction (XRD) analysis at $40 \mathrm{kV}$ and $40 \mathrm{~mA}$ using an M03X-HF22 diffractometer (Mac Science Co. Ltd.). The precipitated metal nanoparticles and $\mathrm{TiO}_{2}$ crystallites were examined by transmission electron microscopy (TEM) and EDX analysis using an HF-2000 (Hitachi Co. Ltd.).

\section{RESULTS AND DISCUSSION}

AlN-doped CaBBAT bulk glass (thickness: $1 \mathrm{~mm}$ ) was black and had little transparency. The absorption coefficient at 300-2000 $\mathrm{nm}$ was over $60 \mathrm{~cm}^{-1}$. Powder DTA measurements showed that the $T_{\mathrm{g}}$ of the AlN-doped CaBBAT glass was $587{ }^{\circ} \mathrm{C}$, which was higher than that of AlN-free $\mathrm{CaB}$ BAT glass $\left(570{ }^{\circ} \mathrm{C}\right) .{ }^{11}$ TEM images of the AlN-doped CaBBAT glass (Fig. 1) show many spherical nanoparticles that were uniformly dispersed in the glass matrix. The average diameter of the metal nanoparticles was $384 \mathrm{~nm}$, and the standard deviation was estimated to be $69 \mathrm{~nm}$. The inset shows an electron diffraction pattern of the amorphous region. Since only a halo pattern was observed, the surrounding glass matrix was clearly amorphous with no crystallites. The TEM images show a contrast between the areas surrounding the nanoparticles and other amorphous regions. This contrast indicates a difference in electron density and shows that the density of the area surrounding a nanoparticle, which is also an amorphous structure, is lower than that of the other amorphous regions. This suggests that the migration of $\mathrm{Bi}$, which is a heavy element, occurred and that some defects were formed at the interface between the nanoparticle and the amorphous matrix.

Figure 2 shows the EDX spectra of the AlN-doped CaBBAT glass shown in Fig. 1. The concentration of $\mathrm{Bi}$ in the nanoparticles was much higher than that in other areas. Note

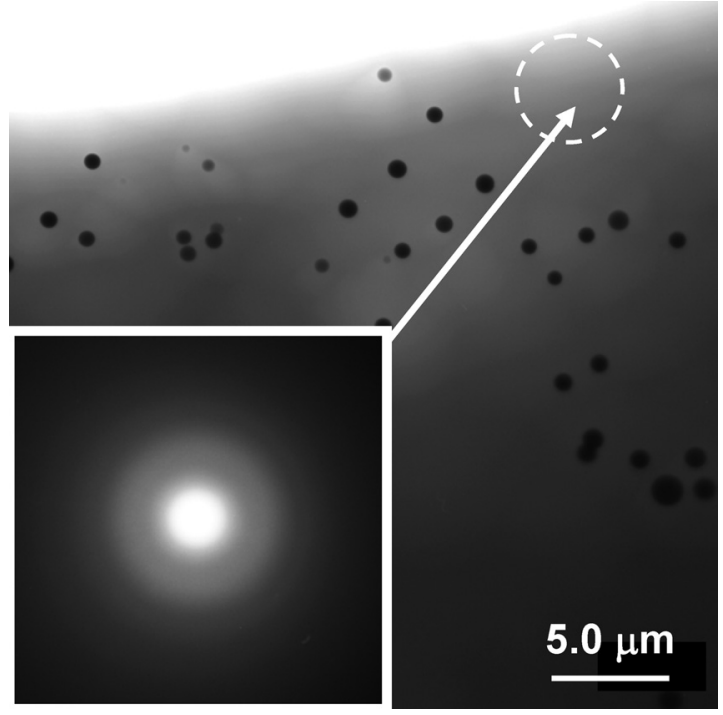

FIG. 1. TEM image of AlN-doped CaBBAT glass. Inset shows the electron diffraction pattern of the amorphous region (dashed circles).

that little oxygen was observed in the nanoparticles. The EDX spectrum also shows that the nanoparticles consisted of Bi metal, which confirmed that Bi metal nanoparticles were precipitated in the AlN-doped CaBBAT glass. The probable reaction for the conversion of $\mathrm{Bi}_{2} \mathrm{O}_{3}$ to $\mathrm{Bi}$ metal is
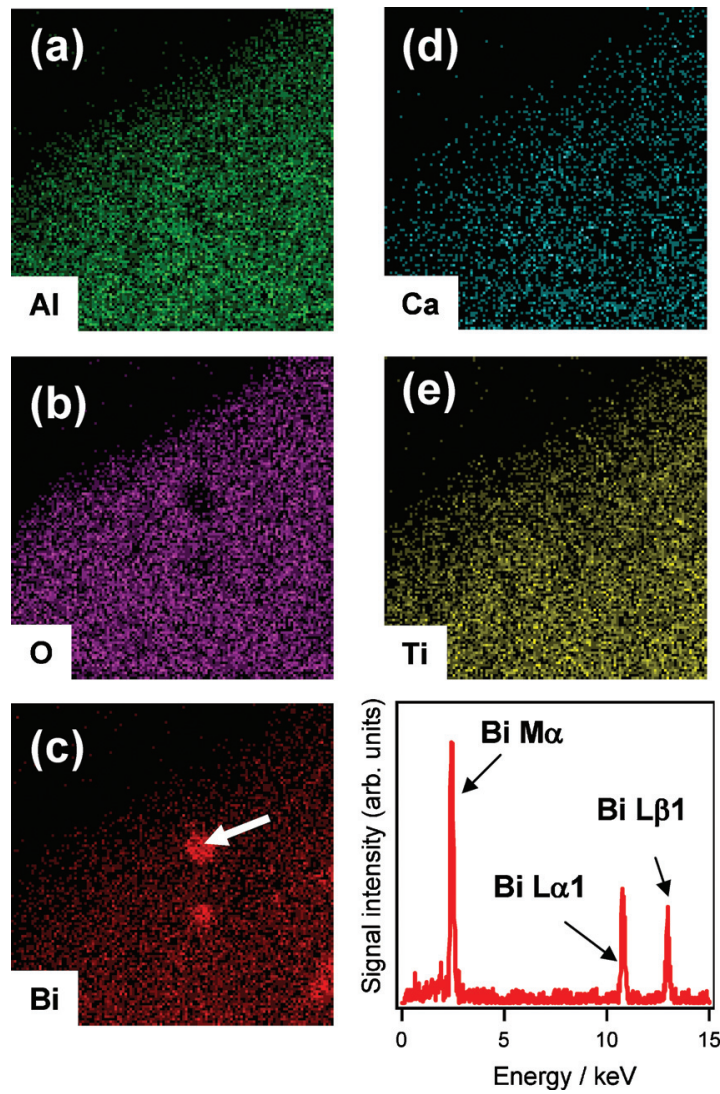

FIG. 2. (Color) EDX map of the Bi-precipitated CaBBAT glass. EDX maps of (a) aluminum, (b) oxygen, (c) bismuth, (d) calcium, and (e) titanium. The EDX pattern of a bismuth nanoparticle is also shown. 


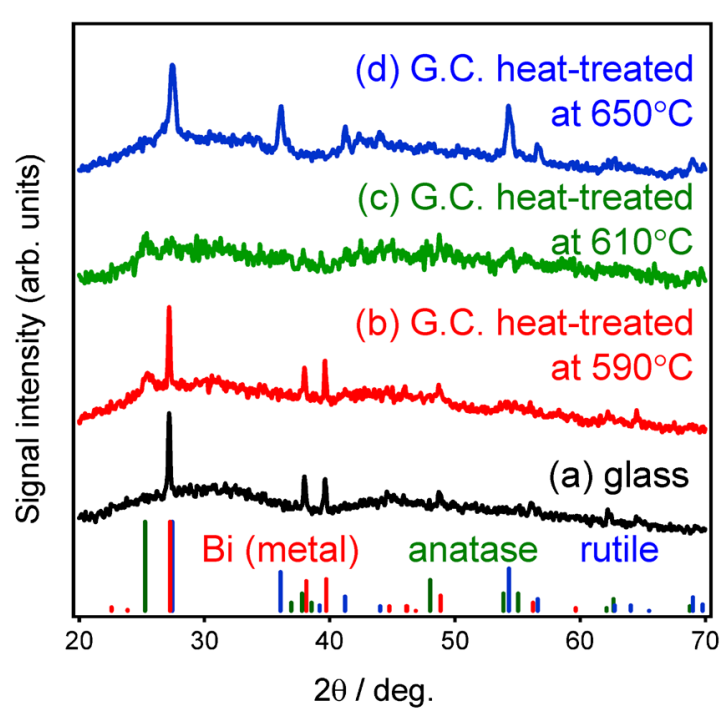

FIG. 3. (Color online) XRD patterns of (a) AlN-doped CaBBAT glass and of glass-ceramics (G.C.) heat-treated for $3 \mathrm{~h}$ at (b) $590{ }^{\circ} \mathrm{C}$, (c) $610^{\circ} \mathrm{C}$, and (d) $650{ }^{\circ} \mathrm{C}$. The JCPDS patterns of metal bismuth, anatase, and rutile are also shown.

$$
\begin{aligned}
2 \mathrm{AlN}+2 \mathrm{Bi}_{2} \mathrm{O}_{3} \rightarrow & \mathrm{Al}_{2} \mathrm{O}_{3}+4 \mathrm{Bi}+\mathrm{gas}\left(\mathrm{NO}+\mathrm{NO}_{2} \text { or } \mathrm{N}_{2}\right. \\
& \left.+\frac{3}{2} \mathrm{O}_{2}\right) .
\end{aligned}
$$

Since any generated gas could easily have escaped during melting, there is no direct evidence for the formation of $\mathrm{NO}_{\mathrm{x}}$ or $\mathrm{N}_{2}$. Nevertheless, the results indicate that the addition of nitride to the glass melt resulted in the reduction of $\mathrm{BiO}_{2}$ to $\mathrm{Bi}$ metal and formation of $\mathrm{Al}_{2} \mathrm{O}_{3}$. Since the bond energy of $\mathrm{Al}_{2} \mathrm{O}_{3}$ is higher than that of $\mathrm{Bi}_{2} \mathrm{O}_{3}$, the $T_{\mathrm{g}}$ of AlNdoped glass should be higher than that of AlN-free glass as a result of the reduction in $\mathrm{Bi}_{2} \mathrm{O}_{3}$ and the formation of $\mathrm{Al}-\mathrm{O}$ bonds. Well-sized metal nanoparticles were uniformly dispersed in the glass matrix, thereby confirming that the selfassembly of nanoparticle structures occurred in the glass matrix.

Figure 3 shows the XRD patterns of the AlN-doped CaBBAT glass (a) and of the glass-ceramic heat-treated at $590{ }^{\circ} \mathrm{C}(\mathrm{b}), 610{ }^{\circ} \mathrm{C}$ (c), and $650{ }^{\circ} \mathrm{C}$ (d). The Joint Committee on Powder Diffraction Standards (JCPDS) patterns of metal $\mathrm{Bi}$, anatase, and rutile are shown for comparison. The diffraction peaks attributed to $\mathrm{Bi}$ metal are observed in the AlN-doped glass (a) and in glass-ceramic (b). Note that anatase diffractions are also observed in glass-ceramic (b), which was heat-treated at around the $T_{\mathrm{g}}$. Previous reports showed that although AlN-free CaBBAT glass-ceramics have lower $T_{\mathrm{g}}$ values, no precipitation was observed in these glass-ceramics at $590{ }^{\circ} \mathrm{C} .{ }^{11}$ Since there is a clear interface between the Bi nanoparticles and the surrounding amorphous region, it is speculated that the migration of cations occurs easily at the interface, which would induce nucleation. We have therefore concluded that $\mathrm{TiO}_{2}$ can be easily precipitated from a metal-precipitated glass matrix at lower temperatures. However, the diffraction pattern of the rutile phase, rather than that of $\mathrm{Bi}$ metal, was observed in the XRD patterns in (a)

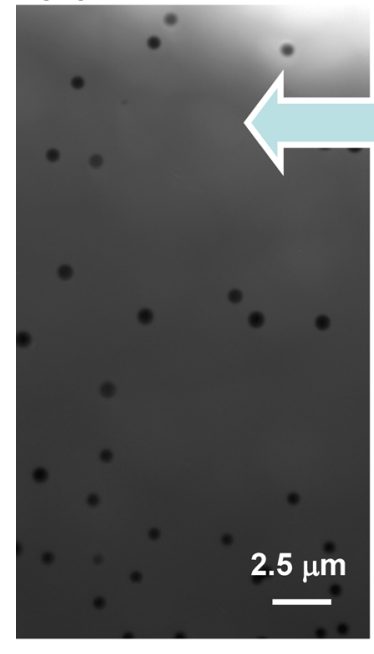

(b)

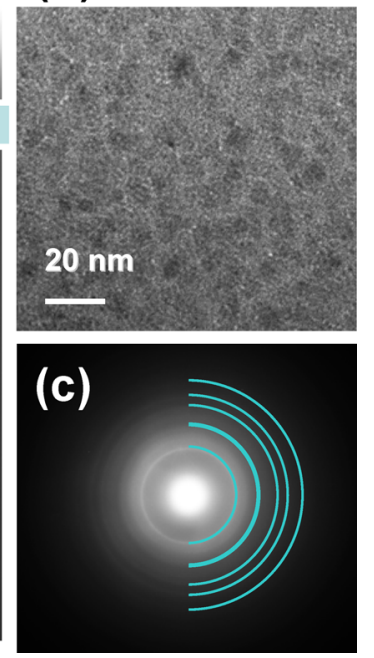

FIG. 4. (Color online) (a) TEM image of AlN-doped CaBBAT glass-ceramic heat-treated at $590{ }^{\circ} \mathrm{C}$ for $3 \mathrm{~h}$; (b) HRTEM image of CaBBAT glassceramic; and (c) electron diffraction pattern of the region in Fig. 4(b). Solid curves show the diffraction of anatase for comparison.

(c) and (d). These diffraction patterns indicate that the precipitated $\mathrm{Bi}$ nanoparticles can be oxidized in air at higher heat-treatment temperatures.

Figure 4(a) shows a TEM image of the glass-ceramic heat-treated at $590{ }^{\circ} \mathrm{C}$ for $3 \mathrm{~h}$. Nanoparticles of Bi (average diameter: $374 \mathrm{~nm}$; standard deviation: $64 \mathrm{~nm}$ ) were dispersed in the glass-ceramic, as in Fig. 1. Note that there was little change in the size of the precipitated $\mathrm{Bi}$ nanoparticles after heat-treatment. This indicates that the aggregation of metal $\mathrm{Bi}$ did not occur during heat-treatment at temperatures around the $T_{\mathrm{g}}$. However, nanocrystallites were observed in the areas surrounding the $\mathrm{Bi}$ nanoparticles, although the TEM image had a similar landscape. Figure 4(b) shows a high-resolution TEM (HRTEM) image of the glass-ceramic and Fig. 4(c) shows the electron diffraction patterns. From these figures, the precipitated nanocrystallites can be identified as anatase, which is in agreement with the XRD results. The diameters of the anatase nanocrystallites were less than $10 \mathrm{~nm}$, which indicates that the migration of cations at temperatures around the $T_{\mathrm{g}}$ stabilizes the amorphous region by the precipitation of nanocrystallites.

We found that the size of the anatase crystallites was affected by their proximity to precipitated Bi. Figure 5 shows HRTEM images in different regions of the Bi-precipitated glass-ceramic heat-treated at $590{ }^{\circ} \mathrm{C}$ for $3 \mathrm{~h}$. One nanocrystallite (a), which was located close to a Bi nanoparticle, had a diameter of 6-10 nm, but another nanocrystallite (b), which was not close to a Bi nanoparticle, had a diameter of 5-7 nm. Thus, nanocrystallites in the neighborhood of $\mathrm{Bi}$ nanoparticles were larger. This clearly suggests that the migration of cations occurred easily at the interface between the Bi nanoparticles and the surrounding amorphous region and that both nucleation and crystal growth occurred more easily near the interface than in other regions. The nanostructure of the glass depends on various factors such as dopant concentration, chemical composition of the mother glass, preparation atmosphere, and the crystallization process; details will be reported in a separate paper. 
(a)

(b)

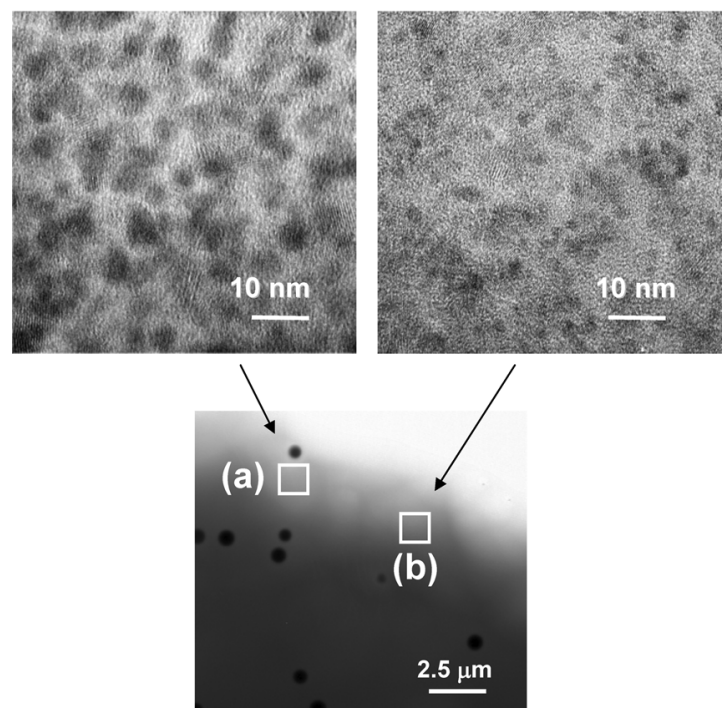

FIG. 5. HRTEM images of different regions of AlN-doped CaBBAT glassceramic: (a) close to Bi nanoparticles and (b) far from Bi nanoparticles.

To date, attempts to precipitate metal nanoparticles and oxide nanocrystallites in the same bulk material have met with little success. It is also difficult to attain the uniform dispersion of nanoparticles in bulk materials of various shapes. However, the metal-dielectric hybrid solid material described here can be made into various shapes such as fibers, lenses, and microbeads; this is difficult with other bulk materials. Although the heat-treatment temperatures required for precipitation of both metal nanoparticles and dielectric nanocrystallites lie within a narrow range, our results show that glass-based materials containing heterogeneous nanostructures can be produced by conventional heat-treatment processes, which are suitable for mass production. The obtained material will be an innovative material containing both metal nanoparticles and dielectric nanocrystallites.

\section{SUMMARY}

We produced glass-ceramics that contained Bi nanoparticles and anatase nanocrystallites. Uniformly dispersed $\mathrm{Bi}$ nanoparticles $(\sim 380 \mathrm{~nm})$ were observed in the AlN-doped glass, and anatase nanocrystallites $(\sim 10 \mathrm{~nm})$ were observed in the glass-ceramics, without the aggregation of the $\mathrm{Bi}$ nanoparticles. The precipitation of anatase was observed at heat-treatment temperatures lower than those used previously, indicating that nucleation occurred at the interface be- tween the metal particles and the amorphous region. Since this technique is based on the reduction in a metal oxide, it can be applied to a variety of glass materials. We believe that precipitation from a mother glass with a self-assembled structure is the best method for the preparation of different types of nanoparticles.

\section{ACKNOWLEDGMENTS}

This work was supported by the Grant-in-Aid for Scientific Research from the Ministry of Education, Science, Sport and Culture, Japan, and the Global Center of Excellence (COE) Program in Tohoku University. The authors thank Dr. T. Miyazaki (Tohoku University) for taking the TEM images and Professor Y. Koike (Tohoku University) for performing the XRD measurements.

${ }^{1}$ M. Brust, M. Walker, D. Bethell, D. J. Schiffrin, and R. Whyman, J. Chem. Soc., Chem. Commun. 7, 801 (1994).

${ }^{2}$ S. M. Nie and S. R. Emery, Science 275, 1102 (1997).

${ }^{3}$ M. C. Daniel and D. Astruc, Chem. Rev. 104, 293 (2004).

${ }^{4}$ W. L. Barnes, A. Dereux, and T. W. Ebbesen, Nature (London) 424, 824 (2003).

${ }^{5}$ X. Michalet, E. F. Pinaud, L. A. Bentolila, J. M. Tsay, S. Doose, J. J. Li, G. Sundaresan, A. M. Wu, S. S. Gambhir, and S. Weiss, Science 307, 538 (2005).

${ }^{6} \mathrm{~K}$. Tachiwana, in Glass Kogaku Handbook, edited by M. Yamane, I. Yasui, M. Wada, Y. Kokubu, R. Terai, K. Kondo, and S. Ogawa (Asakura Syoten, Tokyo, Japan, 1999), p. 568.

${ }^{7}$ K. Matusita and S. Sakka, Phys. Chem. Glasses 20, 81 (1979).

${ }^{8}$ G. W. Arnold, J. Appl. Phys. 46, 4466 (1975).

${ }^{9}$ K. Shioya, T. Komatsu, H. G. Kim, R. Sato, and K. Matusita, J. NonCryst. Solids 189, 16 (1995)

${ }^{10}$ G. H. Beall and L. R. Pinckney, J. Am. Ceram. Soc. 82, 5 (1999).

${ }^{11}$ H. Masai, T. Fujiwara, H. Mori, and T. Komatsu, Appl. Phys. Lett. 90, 081907 (2007).

${ }^{12}$ H. Masai, T. Fujiwara, and H. Mori, Appl. Phys. Lett. 92, 141902 (2008).

${ }^{13}$ H. Masai, T. Toda, Y. Takahashi, and T. Fujiwara, Appl. Phys. Lett. 94, 151910 (2009).

${ }^{14}$ H. Masai, T. Toda, T. Ueno, Y. Takahashi, and T. Fujiwara, Appl. Phys. Lett. 94, 151908 (2009).

${ }^{15}$ W. L. Sha, C. H. Liu, and P. R. Alfano, Opt. Lett. 19, 1922 (1994).

${ }^{16}$ F. Hide, B. J. Schwartz, M. A. Diaz-Garcia, and A. J. Heeger, Chem. Phys. Lett. 256, 424 (1996).

${ }^{17}$ H. Cao, Y. G. Zhao, H. C. Ong, S. T. Ho, J. Y. Dai, J. Y. Wu, and R. P. H. Chang, Appl. Phys. Lett. 73, 3656 (1998).

${ }^{18}$ E. M. Vogel, M. J. Weber, and D. M. Krol, Phys. Chem. Glasses 32, 231 (1991).

${ }^{19}$ J. Bosbach, D. Martin, F. Stietz, T. Wenzel, and F. Trager, Appl. Phys. Lett. 74, 2605 (1999).

${ }^{20}$ J. R. Qiu, M. Shirai, T. Nakaya, J. H. Si, X. W. Jiang, C. S. Zhu, and K. Hirao, Appl. Phys. Lett. 81, 3040 (2002).

${ }^{21}$ D. Oku, T. Honma, T. Komatsu, K. Aoki, and K. Oda, Proceedings of the Annual Meeting of the Ceramic Society of Japan (2008), p. 23 (in Japanaese).

${ }^{22}$ H. Masai, S. Mizuno, T. Fujiwara, H. Mori, and T. Komatsu, Opt. Express 16, 2614 (2008). 